\title{
An Optimal Investment Strategy and Multiperiod Deposit Insurance Pricing Model for Commercial Banks
}

\author{
Grant E. Muller (iD) \\ Department of Mathematics and Applied Mathematics, University of the Western Cape, Private Bag X17, Bellville, \\ Cape Town 7535, South Africa \\ Correspondence should be addressed to Grant E. Muller; gemuller@uwc.ac.za
}

Received 3 November 2017; Revised 14 February 2018; Accepted 19 March 2018; Published 2 May 2018

Academic Editor: Lucas Jodar

Copyright (C) 2018 Grant E. Muller. This is an open access article distributed under the Creative Commons Attribution License, which permits unrestricted use, distribution, and reproduction in any medium, provided the original work is properly cited.

\begin{abstract}
We employ the method of stochastic optimal control to derive the optimal investment strategy for maximizing an expected exponential utility of a commercial bank's capital at some future date $T>0$. In addition, we derive a multiperiod deposit insurance (DI) pricing model that incorporates the explicit solution of the optimal control problem and an asset value reset rule comparable to the typical practice of insolvency resolution by insuring agencies. By way of numerical simulations, we study the effects of changes in the DI coverage horizon, the risk associated with the asset portfolio of the bank, and the bank's initial leverage level (deposit-to-asset ratio) on the DI premium while the optimal investment strategy is followed.
\end{abstract}

\section{Introduction}

Stochastic optimization theory is an extremely important tool to finance as it can be used to solve a vast array of stochastic optimization problems. In banking, specifically, numerous authors have applied the stochastic optimal control technique to solve a variety of optimization problems. Common types of banking optimization problems solved with this approach are optimal asset allocation and optimal capital adequacy management problems. The former entails investing bank funds in assets with the goal of reaching an optimal fund level, while the latter involves optimizing the capital adequacy ratios. The Basel Committee on Banking Supervision introduced the capital adequacy ratios as a measure of the financial strength of banks and other financial institutions.

Optimization problems as described above can, for instance, be observed in the papers Fouche et al. [1], Mukuddem-Petersen and Petersen [2,3], Muller and Witbooi [4], and Chakroun and Abid [5]. Under Basel II, Fouche et al. [1] modelled the capital adequacy ratios and studied an optimal control problem in which they derived an optimal asset allocation strategy for the non-risk-based Leverage Ratio on a given time interval. In particular, Fouche et al. [1] determined the optimal expected terminal utility of the Leverage Ratio and derived the asset allocation strategy that makes it possible to maximize the expected terminal utility of the Leverage Ratio on the given time interval. In their paper [2], Mukuddem-Petersen and Petersen studied a banking problem related to the optimal risk management of banks in a stochastic dynamic setting. The authors of [2] particularly minimized market and capital adequacy risk that, respectively, involves the safety of the securities held and the stability of sources of funds. In this regard, Mukuddem-Petersen and Petersen [2] suggested an optimal portfolio choice and rate of bank capital inflow that will keep the loan level as close as possible to an actuarially determined reference process. This setup leads to a nonlinear stochastic optimal control problem whose solution they determined via the dynamic programming algorithm. In Mukuddem-Petersen and Petersen [3] the authors derived the dynamics of the risk-based Total Capital Ratio or CAR in a stochastic setting. MukuddemPetersen and Petersen [3] further demonstrated how the CAR can be optimized in terms of bank equity allocation and the rate at which additional debt and equity are raised. In their analysis, Mukuddem-Petersen and Petersen [3] employed the dynamic programming algorithm for stochastic optimization. Muller and Witbooi [4] maximized an expected utility of a commercial bank's asset portfolio/total asset value at a future date by finding the optimal amounts of capital for investment in different assets. Under the optimal investment 
strategy, the authors of [4] monitored the level of the bank's CAR numerically. In addition, by controlling the capital of the bank, Muller and Witbooi [4] derived a modified expression for the bank's asset portfolio under which the CAR will remain fixed at exactly the Basel III prescribed minimum level of $8 \%$. Chakroun and Abid [5] addressed the problem of optimal portfolio choice for banks, for which the bank's shareholders have a power utility function and the financial market consists of a bank account, securities, and loans. Chakroun and Abid [5] derived the solution to their problem by following the dynamic programming principle. The authors of [5] performed a simulation with their optimal solution with parameters based on the maximum likelihood method. The simulation confirms the practical potential of the results and shows that this model can adequately account for the essential aspects of the bank. van Schalkwyk and Witbooi [6] studied a control problem related to bank liquidity management in a jump diffusion setting. Their paper [6] has close connections with the aforementioned literature in the sense that it established optimal liquidity and a rate of depository consumption that is deemed important during a (random) auditing process of the reserve requirements. The authors of [6] particularly investigate the interplay between a commercial bank and a central bank and what effects the interplay has on the money supply between the two institutions as well as the Liquidity Coverage Ratio (LCR). The LCR was introduced under the Basel III Accord (see [7]) to promote resilience against potential liquidity disruptions over a 30-day horizon (short-term stress scenario) [7]. Their motivation for studying the dynamics of the LCR is to show that, in principle, banks are able to control their liquidity by following an appropriate provisioning strategy. In doing so, the LCR does not fall below an acceptable level.

The purpose of deposit insurance (DI) is to protect banks' depositors against the risks associated with the failure of banks and other depository institutions. DI claims from a pool of funds to which every depository institution regularly contributes and will cover only a fixed maximum amount per bank depositor.

The feeling of security that a bank's depositors have when their deposits are insured reduces the type of fear that caused bank runs in the 1930s. The DIF number of a bank serves as a measure of how a bank's assets compare to those of problematic banks appearing on the Federal Deposit Insurance Corporation's (FDIC) quarterly issued "Problem Banks List." The FDIC could borrow funds from the Treasury Department and, hence, can not run out of funds. However, if large losses are suffered, remaining banks will have to pay higher DI premiums in the years to come.

In 1977, Merton [8] suggested an analogy between DI and a put option to value DI contracts. Since Merton's [8] analogy, many authors have modelled DI as a one-period European put option. Examples of modelling DI in this way can, for instance, be observed in the papers [9-14]. In the aforementioned papers, the formula for the put option is derived under the assumption that, at the time of the audit, which could be either deterministic or stochastic, the put option is exercised if the insured institution is found to be insolvent. The deposit insuring agent renegotiates the terms for the next period in the case of the insured institution being solvent. The first authors to depart from the tradition of modelling DI as a one-period European put option were Allen and Saunders [15]. According to Allen and Saunders [15], DI can be described as a callable put in the sense that DI is a perpetual put option with the insuring agent holding the right to terminate the put prematurely. In the paper [16] of Duan and $\mathrm{Yu}$, the authors propose an alternative way of interpreting DI in a multiperiod framework. The defaulting banks in [16] are assumed to have their assets reset to the level of the outstanding deposits plus accrued interests when an insolvency resolution occurs. According to the DI contract, the amount required to reset the assets is the legal liability of the insuring agent. Historical data on deposit insurance from the US supports this setup [16]. The purchase-andassumption method or, alternatively, the government assisted merger method was used to resolve the majority of defaulting depository institutions [16]. The paper of Bartholomew [17] reported data for 1730 thrifts that were resolved from 1980 to 1990. Of the 1730 thrifts, $85.4 \%$ were resolved through this form of reorganization [17]. According to Table 125 of the FDIC's 1990 Annual Report, 1813 banks were closed during the period from 1945 through 1990. Among these, 69.6\% of banks were resolved through this form of reorganization [17].

According to Duan and Yu [16], the majority of defaulting banks continue to operate with DI after reorganization. Such banks can be regarded as receiving an at-the-money put option at the point of insolvency resolution [16]. Thus, according to Duan and Yu [16], DI can be viewed as a stream of one-period Merton-type put options for which the asset value resets occasionally. Whenever the value of banks' assets rises above the level required by a threshold asset-to-debt ratio, the banks will start to pay out cash dividends. The asset-to-debt ratio is used to determine the maximum level of paid-in capital above which bank shareholders will start to distribute cash dividends [16]. According to Duan and Yu [16], the threshold level is dictated by the dividend policy of the bank.

By definition, bank capital is the difference between the value of banks' assets and liabilities and represents the banks' net worth or value to its investors. The purpose of this paper, which is a rework of Chapter 8 of the author's Ph.D. thesis (see [18]) titled "Optimal Asset Allocation and Capital Adequacy Management Strategies for Basel III Compliant Banks," is to

(i) study a bank capital optimization problem using the classical tools of stochastic optimal control as optimization engine;

(ii) derive a multiperiod deposit insurance pricing model that incorporates (i) the optimal solution of the control problem and (ii) an asset value reset rule similar to those incorporated by the models of Duan and $\mathrm{Yu}[16,19]$.

To the best of our knowledge, the literature has not reported a research paper addressing the problem described above, making our contribution a novel one. In our paper, we consider a bank that is able to continuously raise capital that is invested in a market consisting of two risky assets 
(marketable security and loan) and a riskless asset (treasury security), and where the interest rate is constant. Our goal is to derive the optimal investment strategies in the bank assets that maximize an expected utility of the bank's capital at some future date $T>0$. We try to find an explicit solution using an exponential utility function similar to the one considered by Devolder et al. [20]. Furthermore, we derive the DI pricing model by following the options based approach used in the papers Merton $[8,9]$ and Duan and Yu $[16,19]$. Our pricing model incorporates the optimal investment strategies for the different bank assets in the sense that the expressions describing these strategies are embedded in the formula for the bank's asset portfolio, and hence, in the estimate for the DI premium. The latter is calculated through Monte Carlo simulations. In addition, the pricing model incorporates an asset value reset rule similar to those of Duan and $\mathrm{Yu}[16,19]$. More specifically, the asset value reset rule involves resetting the value of the asset portfolio to the face value of the insured deposits plus accrued interest should the bank be found insolvent at the time of the bank audit.

The rest of our paper is organized as follows. In Section 2 we cover some basic theory on commercial banking. In particular, we present the stylized balance sheet of commercial banks. This includes a brief description of the items that make up the banks' balance sheets. In Section 3 we describe the financial market in which our bank operates. Here we introduce models for the bank's assets and liabilities and we derive an expression for the asset portfolio of the bank. This allows us to derive a stochastic model for the bank capital, which we also present here. In Section 4 we formulate and solve the optimal control problem and then present a simulation study illustrating the behaviours of the optimal investment strategy and optimized bank capital graphically. We derive the multiperiod DI pricing model in Section 5. We present some simulations that were performed with the pricing model towards the end of this section. Concluding remarks are given in Section 6.

\section{The Commercial Banking Model}

We consider a complete and frictionless financial market that is continuously open over a fixed time interval $[0, T]$. We assume throughout that we are working with a probability space $\left(\Omega, \mathscr{F},\{\mathscr{F}(t)\}_{t \geq 0}, \mathbb{P}\right)$, where $\mathbb{P}$ is the real world probability. The Brownian motions $W_{D}$ and $W_{i}$, for $i=1,2,3$, appearing in the dynamics of the bank items (introduced in Section 3) are assumed to be defined on the probability space $\left(\Omega, \mathscr{F},\{\mathscr{F}(t)\}_{t \geq 0}, \mathbb{P}\right)$. The filtration $\{\mathscr{F}(t)\}_{t \geq 0}$ is generated by the Brownian motions and satisfies the usual conditions.

The stylized balance sheet of commercial banks records the assets and liabilities of the banks. A bank's assets and liabilities are balanced by its capital. Therefore, at time $t \geq 0$, the stylized balance sheet may be represented by

$$
R(t)+S(t)+L(t)=D(t)+B(t)+C(t),
$$

where the variables $R, S, L, D, B$, and $C$ represent the values of reserves, securities, loans, deposits, borrowings, and capital, respectively. All of the aforementioned variables are regarded as stochastic processes $[2,4,21]$.
Whether commercial banks make profit depends on their ability to properly manage the asset side of their balance sheets. This is determined by two factors, namely, the amount of resources (capital, retained earnings, and deposits) banks have available to invest and their attitude towards risk and return. Banks must therefore allocate their resources optimally among their assets. Below we explain each of the items on the balance sheet of a commercial bank.

The banks' reserves are the vault cash of the banks plus the amount of money they are obliged to deposit at the central bank. The vault cash is the money used to meet the day-today currency withdrawals by the banks' customers. Securities can be divided into two categories, namely, treasury securities (treasuries) and marketable securities. Treasuries are bonds issued by national treasuries in most countries as a means of borrowing money to meet government expenditures not covered by tax revenues. Marketable securities, on the other hand, are stocks and bonds that can be converted to cash quickly and easily. The types of loans granted by the bank include business loans, mortgage loans, and consumer loans. Consumer loans include credit extended by the bank for credit card purchases. Mortgages are long term loans used to buy a house or land, where the house or land acts as collateral. Business loans are taken out by firms that borrow funds to finance their inventories, which act as collateral for the loan. Loans which have collateral (secured loans) have a lower interest rate associated with it compared to a loan which has no collateral (unsecured loans).

Bank capital is raised by selling new equity, retaining earnings, and issuing debt or building up loan loss reserves. The dynamics of bank capital is stochastic in nature because it depends in part on the uncertainty related to debt- and shareholder contributions. In theory, the bank can decide on the rate at which debt and equity is raised.

Under Basel III the banks' capital $C$ has the form

$$
C(t)=C_{\mathrm{T} 1}(t)+C_{\mathrm{T} 2}(t),
$$

where $C_{\mathrm{T} 1}(t)$ and $C_{\mathrm{T} 2}(t)$ are Tier 1 and Tier 2 capital, respectively $[4,22,23]$.

Basel III defines Tier 1 capital as the sum of Common Equity Tier 1 capital and Additional Tier 1 capital. Common Equity Tier 1 capital is defined as the sum of common shares issued by the bank that meet the criteria for classification as common shares for regulatory purposes, stock surplus resulting from the issue of instruments included in Common Equity Tier 1 capital, retained earnings, accumulated other comprehensive income and other disclosed reserves, common shares issued by consolidated subsidiaries of the bank and held by third parties that meet the criteria for inclusion in Common Equity Tier 1 capital, and regulatory adjustments applied in the calculation of Common Equity Tier 1 capital. Additional Tier 1 capital is the sum of instruments issued by the bank that meet the criteria for inclusion in Additional Tier 1 capital (and are not included in Common Equity Tier 1 capital), stock surplus resulting from the issue of instruments included in Additional Tier 1 capital, instruments issued by consolidated subsidiaries of the bank and held by third parties that meet the criteria for inclusion in Additional Tier 
1 capital and are not included in Common Equity Tier 1 capital, and regulatory adjustments applied in the calculation of Additional Tier 1 capital [4, 22, 23].

Tier 2 capital is defined as the sum of the following elements: instruments issued by the bank that meet the criteria for inclusion in Tier 2 capital (and are not included in Tier 1 capital), stock surplus resulting from the issue of instruments included in Tier 2 capital, instruments issued by consolidated subsidiaries of the bank and held by third parties that meet the criteria for inclusion in Tier 2 capital and are not included in Tier 1 capital, certain loan loss provisions, and regulatory adjustments applied in the calculation of Tier 2 capital [4, 22, 23].

A bank's deposits is the money that the bank's customers place in the banking institution for safekeeping. Deposits are made into deposit accounts at a banking institution. Examples of deposit accounts are savings accounts, checking accounts, and money market accounts. The deposit account holder has the right to withdraw any deposited funds, as set forth in the terms and conditions of the account. Deposits are considered to be the main liabilities of the bank.

The term borrowings refers to the funds that commercial banks borrow from other banks and the central bank.

\section{The Financial Market Setting}

We assume that it is possible for the bank to continuously raise capital at a rate $d K(t)$, which is invested in a market consisting of three types of assets, namely, a treasury, a marketable security, and a loan.

The price of the treasury at time $t \geq 0$ is denoted by $S_{1}(t)$. We assume its dynamics to evolve according to the ordinary differential equation (ODE)

$$
\frac{d S_{1}(t)}{S_{1}(t)}=r d t, \quad S_{1}(0)>0 .
$$

We assume that the interest rate $r$ in the financial market is a positive constant.

At time $t \geq 0$, the price of the marketable security is denoted by $S_{2}(t)$. Its dynamics are assumed to be modelled by the stochastic differential equation (SDE)

$$
\frac{d S_{2}(t)}{S_{2}(t)}=\left(r+m_{1}\right) d t+\sigma_{1} d W_{1}(t), \quad S_{2}(0)>0
$$

where $m_{1}$ and $\sigma_{1}$ are assumed to be positive constants.

The loan is to be amortized over a period $[0, T]$. Its value at time $t \geq 0$ is denoted by $S_{3}(t)$, and we assume that its dynamics evolves according the SDE

$$
\begin{aligned}
\frac{d S_{3}(t)}{S_{3}(t)}=\left(r+m_{2}\right) d t+\sigma_{2} d W_{2}(t)+\sigma_{3} d W_{3}(t) & \\
& S_{3}(0)>0
\end{aligned}
$$

where $m_{2}, \sigma_{2}$, and $\sigma_{3}$ are positive constants.

We now introduce the total asset value or asset portfolio of the bank. Let $A(t)$ denote the value of the bank's asset portfolio at time $t \geq 0$. The dynamics of the asset portfolio can be described by the SDE

$$
\begin{aligned}
d A(t)= & \sum_{j=1}^{3} \theta_{j}(t) \frac{d S_{j}(t)}{S_{j}(t)}+d K(t) \\
= & \theta_{1}(t) \frac{d S_{1}(t)}{S_{1}(t)}+\theta_{2}(t) \frac{d S_{2}(t)}{S_{2}(t)}+\theta_{3}(t) \frac{d S_{3}(t)}{S_{3}(t)} \\
& +d K(t)
\end{aligned}
$$

(see $[4,24-26]$ for instance). In (6), the quantities $\theta_{1}(t)$, $\theta_{2}(t)$, and $\theta_{3}(t)$ denote the amounts of capital invested in the treasury, marketable security, and loan, respectively.

If we assume that the influx of capital can be described by the ODE

$$
d K(t)=c d t, \quad K(0)>0,
$$

where $c$ is a positive constant, then making use of the models for $S_{1}(t), S_{2}(t)$, and $S_{3}(t)$, the formula describing the asset portfolio takes the form

$d A(t)$

$$
\begin{aligned}
= & {\left[\theta_{1}(t) r+\theta_{2}(t)\left(r+m_{1}\right)+\theta_{3}(t)\left(r+m_{2}\right)+c\right] d t } \\
& +\theta_{2}(t) \sigma_{1} d W_{1}(t)+\theta_{3}(t) \sigma_{2} d W_{2}(t) \\
& +\theta_{3}(t) \sigma_{3} d W_{3}(t) .
\end{aligned}
$$

We assume that the bank's liabilities come only in the form of the deposits, which we assume to evolve according to the SDE

$$
d D(t)=\mu_{D} d t+\sigma_{D} d W_{D}(t), \quad D(0)>0,
$$

with $\mu_{D}$ and $\sigma_{D}$ both being positive constants.

Then, at time $t \geq 0$, the bank's capital $C(t)$ can be defined as

$$
C(t)=A(t)-D(t) .
$$

The SDE governing $C(t)$ is therefore

$$
d C(t)=d A(t)-d D(t)
$$

We import the SDEs (8) and (9) into the latter SDE to arrive at

$$
\begin{aligned}
& d C(t)=\left[\theta_{1}(t) r+\theta_{2}(t)\left(r+m_{1}\right)+\theta_{3}(t)\left(r+m_{2}\right)\right. \\
& \left.\quad+c-\mu_{D}\right] d t+\theta_{2}(t) \sigma_{1} d W_{1}(t)+\theta_{3}(t) \sigma_{2} d W_{2}(t) \\
& +\theta_{3}(t) \sigma_{3} d W_{3}(t)-\sigma_{D} d W_{D}(t) .
\end{aligned}
$$

\section{The Control Problem and Its Optimal Solution}

We now present the optimal control problem and derive its solution. We seek an investment strategy that maximizes the expected utility of the bank's capital at a future date $T>0$. Mathematically, the stochastic optimal control problem can be stated as follows. 
Problem 1. The objective is to maximize the expected utility of the bank's capital at a future date $T>0$, that is,

$$
\max _{\theta_{2}, \theta_{3}} \mathbb{E}[U(C(T))]
$$

with

$$
\begin{aligned}
& d C(t)=\left[\theta_{1}(t) r+\theta_{2}(t)\left(r+m_{1}\right)+\theta_{3}(t)\left(r+m_{2}\right)\right. \\
& \left.+c-\mu_{D}\right] d t+\theta_{2}(t) \sigma_{1} d W_{1}(t)+\theta_{3}(t) \sigma_{2} d W_{2}(t) \\
& +\theta_{3}(t) \sigma_{3} d W_{3}(t)-\sigma_{D} d W_{D}(t), \quad C(0)>0
\end{aligned}
$$

where $0 \leq t \leq T$ and $C(0)$ denotes the initial value of the capital, assumed to be a positive constant.

By using the classical tools of stochastic optimal control, we define, for $0<t<T$, the value function of the problem:

$$
H(t, C)=\sup _{\theta_{2}, \theta_{3}} \mathbb{E}[U(C(T) \mid C(t)=C)] .
$$

The value function can be considered as a kind of utility function. The marginal utility of the value function is a constant, while the marginal utility of the original utility function $U(\cdot)$ decreases to zero as $C \rightarrow \infty$ (see Kramkov and Schachermayer [27]). The value function also inherits the convexity of the utility function (see Jonsson and Sircar [28]). Moreover, it is strictly convex for $t<T$ even if $U(\cdot)$ is not.

The maximum principle leads to the Hamilton-JacobiBellman (HJB) equation

$$
\begin{aligned}
& H_{t}+\max _{\theta_{2}, \theta_{3}}\left\{\left[\theta_{1} r+\theta_{2}\left(r+m_{1}\right)+\theta_{3}\left(r+m_{2}\right)+c-\mu_{D}\right]\right. \\
& \cdot H_{C}+\frac{1}{2}\left[\left(\theta_{2} \sigma_{1}\right)^{2}+\left(\theta_{3} \sigma_{2}\right)^{2}+\left(\theta_{3} \sigma_{3}\right)^{2}+\sigma_{D}^{2}\right] \\
& \left.\cdot H_{C C}\right\}=0
\end{aligned}
$$

where the time variable $t$ has been suppressed.

The first-order maximizing conditions for the optimal investment strategies $\theta_{2}$ and $\theta_{3}$ in, respectively, the marketable security and loan are

$$
\begin{aligned}
& \theta_{2}=-\frac{\left(r+m_{1}\right) H_{C}}{\sigma_{1}^{2} H_{C C}}, \\
& \theta_{3}=-\frac{\left(r+m_{2}\right) H_{C}}{\left(\sigma_{2}^{2}+\sigma_{3}^{2}\right) H_{C C}} .
\end{aligned}
$$

Substituting these in (16), we obtain a partial differential equation (PDE) for the value function:

$$
\begin{aligned}
H_{t} & +\left[\theta_{1} r-\frac{\left(r+m_{1}\right)^{2} H_{C}}{\sigma_{1}^{2} H_{C C}}-\frac{\left(r+m_{2}\right)^{2} H_{C}}{\left(\sigma_{2}^{2}+\sigma_{3}^{2}\right) H_{C C}}+c\right. \\
& \left.-\mu_{D}\right] H_{C}+\frac{1}{2}\left[\frac{\left(r+m_{1}\right)^{2} H_{C}^{2}}{\sigma_{1}^{2} H_{C C}^{2}}+\frac{\left(r+m_{2}\right)^{2} \sigma_{2}^{2} H_{C}^{2}}{\left(\sigma_{2}^{2}+\sigma_{3}^{2}\right)^{2} H_{C C}^{2}}\right. \\
& \left.+\frac{\left(r+m_{2}\right)^{2} \sigma_{3}^{2} H_{C}^{2}}{\left(\sigma_{2}^{2}+\sigma_{3}^{2}\right)^{2} H_{C C}^{2}}+\sigma_{D}^{2}\right] H_{C C}=0 .
\end{aligned}
$$

The problem is now solving the PDE in (18) for the value function and placing it in (17) in order to obtain the optimal strategies $\theta_{2}$ and $\theta_{3}$.

This equation admits an explicit solution for a utility function of the form

$$
U(C)=-\frac{1}{g} e^{-g C} \quad \text { (with } g>0 \text { a positive constant } .
$$

Clearly then, like in Devolder et al. [20], we find that

$$
-\frac{U^{\prime \prime}(C)}{U^{\prime}(C)}=g .
$$

We try to find a solution with the structure

$$
H(t, C)=-\frac{1}{g} e^{-g C+b(t)},
$$

with $b(T)=1$. Then

$$
\begin{aligned}
H_{t} & =-\frac{b^{\prime}(t)}{g} e^{-g C+b(t)}, \\
H_{C} & =e^{-g C+b(t)}, \\
H_{C C} & =-g e^{-g C+b(t)} .
\end{aligned}
$$

Substituting the above derivatives in (18), we obtain the separable differential equation

$$
b^{\prime}(t)-\lambda=0
$$

with

$$
\begin{aligned}
\lambda= & g\left[\theta_{1} r+\frac{\left(r+m_{1}\right)^{2}}{\sigma_{1}^{2} g}+\frac{\left(r+m_{2}\right)^{2}}{\left(\sigma_{2}^{2}+\sigma_{3}^{2}\right) g}+c-\mu_{D}\right] \\
& -\frac{1}{2} g^{2}\left[\frac{\left(r+m_{1}\right)^{2}}{\sigma_{1}^{2} g^{2}}+\frac{\left(r+m_{2}\right)^{2} \sigma_{2}^{2}}{\left(\sigma_{2}^{2}+\sigma_{3}^{2}\right)^{2} g^{2}}\right. \\
& \left.+\frac{\left(r+m_{2}\right)^{2} \sigma_{3}^{2}}{\left(\sigma_{2}^{2}+\sigma_{3}^{2}\right)^{2} g^{2}}+\sigma_{D}^{2}\right] .
\end{aligned}
$$

The solution to the above differential equation is

$$
b(t)=\lambda(t-T)+1 .
$$

Finally, the value function becomes

$$
H(t, C)=-\frac{1}{g} e^{-g C+\lambda(t-T)+1} .
$$

The second-order conditions are also fulfilled as

$$
\begin{gathered}
\sigma_{1}^{2} H_{C C}=-\sigma_{1}^{2} g e^{-g C+\lambda(t-T)+1}<0, \\
\left(\sigma_{2}^{2}+\sigma_{3}^{2}\right) H_{C C}=-\left(\sigma_{2}^{2}+\sigma_{3}^{2}\right) g e^{-g C+\lambda(t-T)+1}<0 .
\end{gathered}
$$

Using (17), we derive the optimal amounts of capital for investment in the marketable security and loan, respectively, as

$$
\theta_{2}=-\frac{\left(r+m_{1}\right) e^{-g C+b(t)}}{\sigma_{1}^{2}\left(-g e^{-g C+b(t)}\right)}=\frac{r+m_{1}}{\sigma_{1}^{2} g}
$$




$$
\theta_{3}=-\frac{\left(r+m_{2}\right) e^{-g C+b(t)}}{\left(\sigma_{2}^{2}+\sigma_{3}^{2}\right)\left(-g e^{-g C+b(t)}\right)}=\frac{r+m_{2}}{\left(\sigma_{2}^{2}+\sigma_{3}^{2}\right) g}
$$

The optimal amount of capital to be invested in the treasury is

$$
\theta_{1}=A-\theta_{2}-\theta_{3}=A-\frac{r+m_{1}}{\sigma_{1}^{2} g}-\frac{r+m_{2}}{\left(\sigma_{2}^{2}+\sigma_{3}^{2}\right) g}
$$

The optimal proportions of capital for investment in the marketable security, loan, and treasury are, respectively,

$$
\begin{aligned}
& f_{2}=\frac{\theta_{2}}{A}=\frac{r+m_{1}}{\sigma_{1}^{2} g A} ; \\
& f_{3}=\frac{\theta_{3}}{A}=\frac{r+m_{2}}{\left(\sigma_{2}^{2}+\sigma_{3}^{2}\right) g A} ; \\
& f_{1}=\frac{\theta_{1}}{A}=1-\frac{r+m_{1}}{\sigma_{1}^{2} g A}-\frac{r+m_{2}}{\left(\sigma_{2}^{2}+\sigma_{3}^{2}\right) g A} .
\end{aligned}
$$

We now provide a numerical simulation in order to characterize the optimal investment strategy and illustrate the behaviour of the optimized bank capital. We assume that the bank's asset portfolio consists of a treasury, a marketable security, and a loan. Furthermore, we consider an investment horizon of $T=10$ years and assume that $c$ is fixed at $c=$ 0.0145 . The rest of the parameters of the simulation are

$$
\begin{aligned}
r & =0.065, \\
m_{1} & =0.035, \\
\sigma_{1} & =0.08, \\
m_{2} & =0.045, \\
\sigma_{2} & =0.095, \\
\sigma_{3} & =0.065, \\
\mu_{D} & =0.12, \\
\sigma_{D} & =0.15, \\
g & =25
\end{aligned}
$$

with initial conditions

$$
\begin{aligned}
& A(0)=1, \\
& D(0)=0.80, \\
& C(0)=0.20 .
\end{aligned}
$$

For the parameters listed above, we simulate the solutions $K(t)$ and $b(t)$ of, respectively, (7) and the separable differential equation (23) in Figures 1 and 2. We observe that $K(t)$ is an increasing function of time, while $b(t)$ decreases over time. In Figure 3 we simulate the optimal proportions of capital associated with the solution of Problem 1. We simulate the corresponding optimized capital of the bank along with the assets and deposits in Figure 4. We note that the optimal investment strategy entails diversification of the bank's asset

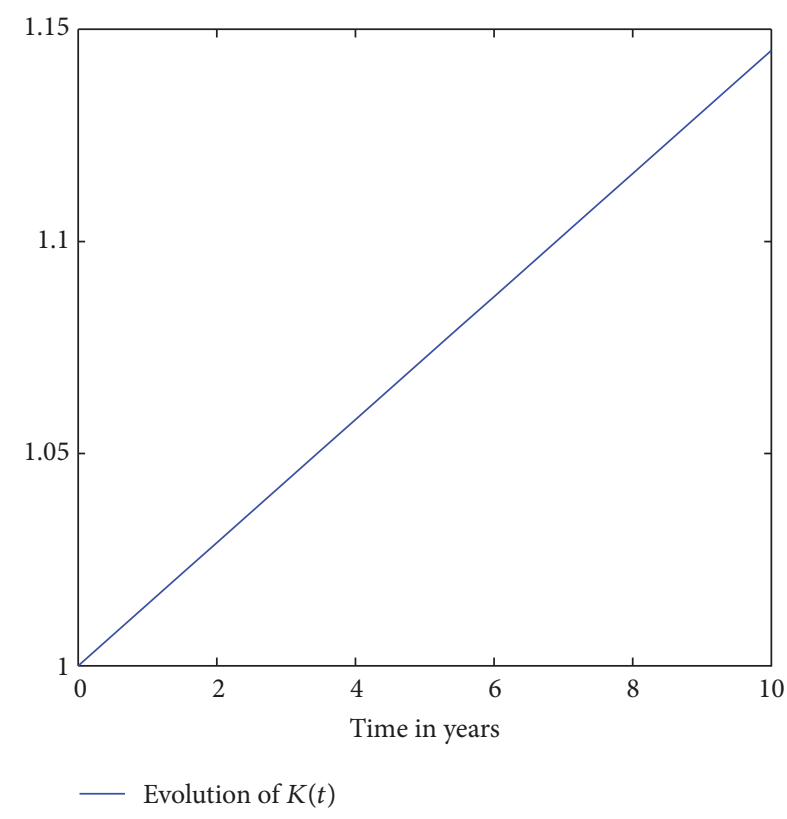

Figure 1: A simulation of $K(t)$ for the parameter $c=0.0145$ and initial condition $K(0)=1$.

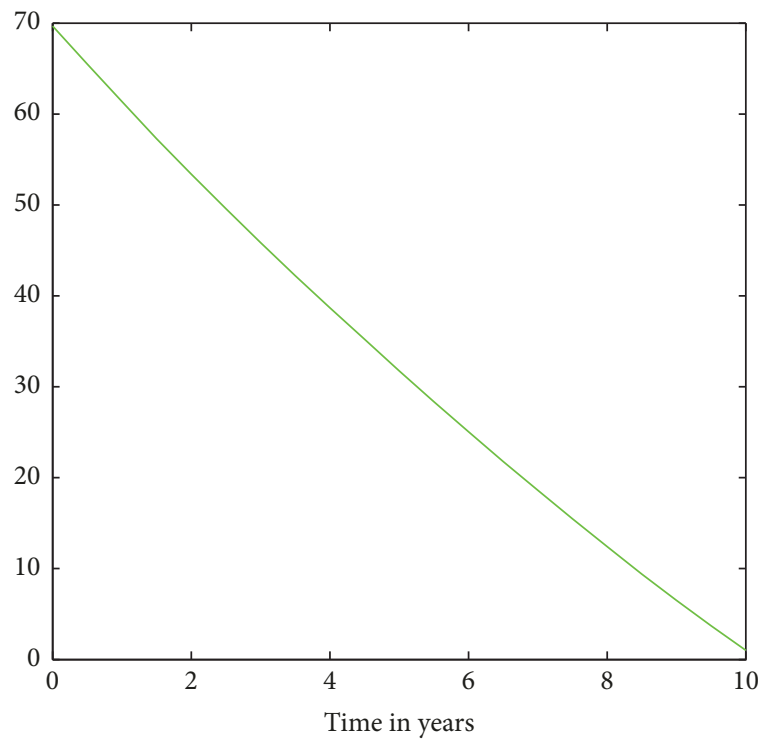

Evolution of $b(t)$

FIgURE 2: A simulation of $b(t)$ for $c=0.0145, r=0.065, m_{1}=0.035$, $\sigma_{1}=0.08, m_{2}=0.045, \sigma_{2}=0.095, \sigma_{3}=0.065, \mu_{D}=0.12, \sigma_{D}=0.15$, and $g=25$.

portfolio. In particular, the bank has to initially invest most of the capital in the risky assets. Over time, the quantities of capital invested in these assets progressively decrease as higher amounts of capital must be invested in the treasury security.

Evidence supporting our result, that is, that the bank needs to diversify its asset portfolio in order to maximize the expected utility of its capital at time $T$, can for instance be the papers Witbooi et al. [21], Muller and Witbooi [4], and 


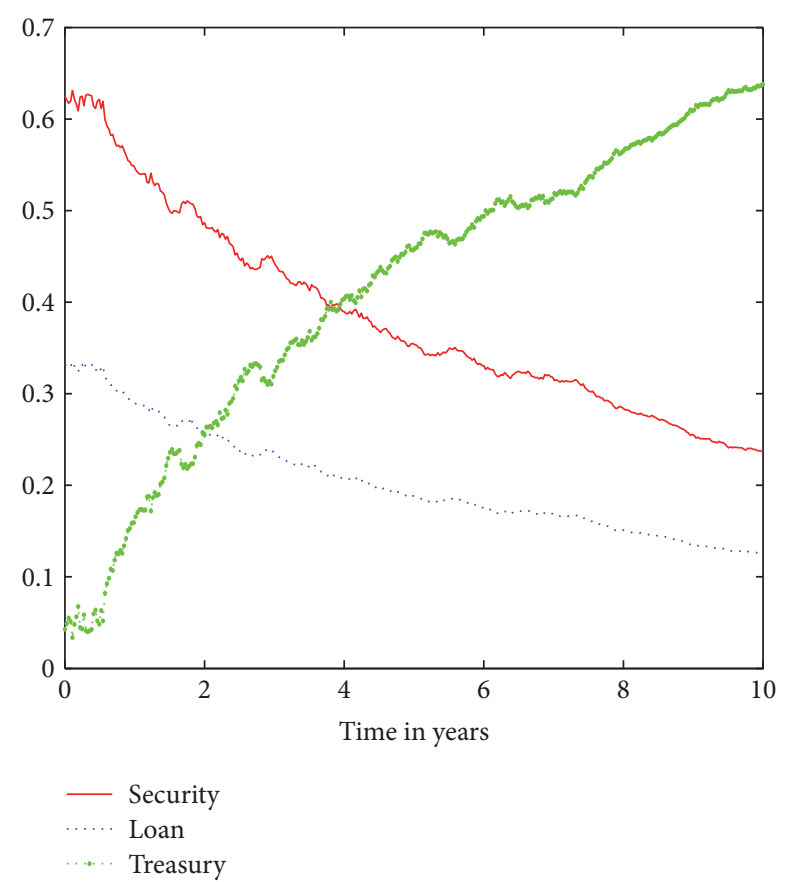

Figure 3: A simulation of the optimal proportions $f_{2}(t), f_{3}(t)$, and $f_{1}(t)$ of capital invested, respectively, in the marketable security, loan, and treasury.

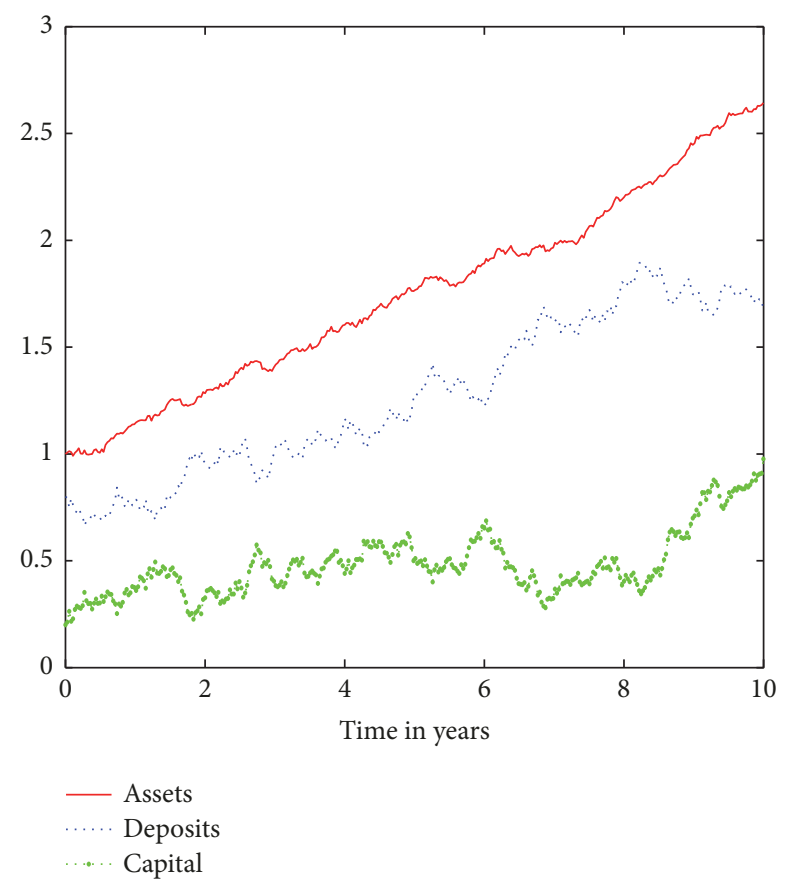

FIGURE 4: A simulation of the optimized bank capital $C(t)$, together with the asset portfolio $A(t)$ and deposits $D(t)$ of the bank.

Chakroun and Abid [5]. In the paper by Witbooi et al. [21], the authors found that, over time, the bank has to diversify away from the loans and towards the treasuries. The bank modelled by Muller and Witbooi [4] has to diversify its asset portfolio away from the risky assets (marketable security and loan) and towards the treasury, while for the banking model considered by Chakroun and Abid [5] on the other hand, the optimal investment strategy is to reduce the amount of funds invested in the treasuries and increase the amount of funds invested in the loans and marketable securities. The diversification strategy in this paper is, to an extent, more in line with the findings of Witbooi et al. [21] and Muller and Witbooi [4] than with those of Chakroun and Abid [5].

\section{The Multiperiod Deposit Insurance Pricing Model}

We now derive the multiperiod DI pricing model. We assume that the bank does not pay any dividends to its shareholders on the interval $[0, T]$. We follow an options based deposit insurance pricing approach similar to Merton $[8,9]$, Ronn and Verma [12], and Duan and Yu [16, 19].

We assume that the bank is audited at times $t(k), k=$ $1,2,3, \ldots, n-1, n$, where $t(k)$ are positive integers such that $0=t(0)<t(1)<t(2)<t(3) \cdots<t(n-1)<t(n)=T$. We further assume that the bank's total asset value is subject to reset at the time of the audit in a way similar to what was the case for the models in the papers [16, 19]. More specifically, the insuring agent adopts a purchase-and-assumption or government assisted merger as a means to conduct insolvency resolution, in which case the insuring agent provides a lump sum transfer to the acquirer of the failing bank. The lump sum is an amount sufficient to cover the face value of the insured deposits plus accrued interest.

If we let the value of the total insured deposits of the bank at time $t$ be denoted by $\widehat{D}(t)$, where $\widehat{D}(t)=\rho D(t)$ and $0 \leq \rho \leq$ 1 , then

$$
d \widehat{D}(t)=\rho d D(t)=\rho\left[\mu_{D} d t+\sigma_{D} d W_{D}(t)\right] .
$$

Since the bank's total asset value is subject to reset at the auditing times, the total asset value will at time $t(k)$ be reset to the value $e^{r t(k)} \widehat{D}(0)$ if $A(t(k))<e^{r t(k)} \widehat{D}(t(k))$ (if the bank is found to be insolvent at time $t(k)$ ), but will follow the SDE in (8) otherwise.

The value of the DI at times $t(k)$, for $k=1,2,3, \ldots, n-1, n$, can be modelled as a put option with strike price $e^{r t(k)} \widehat{D}(t(k))$ and underlying asset price $A(t(k))$ (see [16] for instance). Thus, facing the insuring agent is a stream of put option-like liabilities, each giving rise to a payment denoted by $Q(t(k))$, where

$$
\begin{aligned}
& Q(t(k)) \\
& = \begin{cases}e^{r t(k)} \widehat{D}(t(k))-A(t(k)), & \text { if } A(t(k))<e^{r t(k)} \widehat{D}(t(k)) \\
0, & \text { if otherwise. }\end{cases}
\end{aligned}
$$

The liability facing the insuring agent at time $t(k)$ can thus be generalized to

$$
\begin{aligned}
Q(t(k)) & =\left[e^{r t(k)} \widehat{D}(t(k))-A(t(k))\right]^{+} \\
& =\max \left[0, e^{r t(k)} \widehat{D}(t(k))-A(t(k))\right] .
\end{aligned}
$$

Due to the SDE (8) describing our asset portfolio not being a geometric Brownian process, we will not be able to employ the Black-Scholes [29] formula to price the put 
While generating $1,000,000$ sets, each consisting of a pair of sample paths for $\widehat{D}$ and $A$ on the interval $[0, T]$,

DO

At each $t(k)$, where $k=1,2,3, \ldots, n-1, n$ and $t(1)<t(2)<t(3), \ldots, t(n-1)<t(n)=T$ are positive integers:

Calculate the payoff $\left[e^{r t(k)} \widehat{D}(t(k))-A(t(k))\right]^{+}$for each set consisting of the sample paths of $\widehat{D}$ and $A$.

Using all the sets of sample paths of $\widehat{D}$ and $A$, calculate the average of the payoffs $\left[e^{r t(k)} \widehat{D}(t(\mathrm{k}))-A(t(k))\right]^{+}$as

a proxy to $\mathbb{E}\left[e^{r t(k)} \widehat{D}(t(k))-A(t(k))\right]^{+}$.

Discount the proxy to time zero by multiplying it by $e^{-r t(k)}$.

END

Sum the values of all the discounted proxies calculated at times $t(k)$, where $k=1,2,3, \ldots, n-1, n$.

Divide the sum of the discounted proxies by $n \widehat{D}(0)$.

Algorithm 1: An algorithm for the Monte Carlo simulation method used to estimate $\widehat{\omega}$.

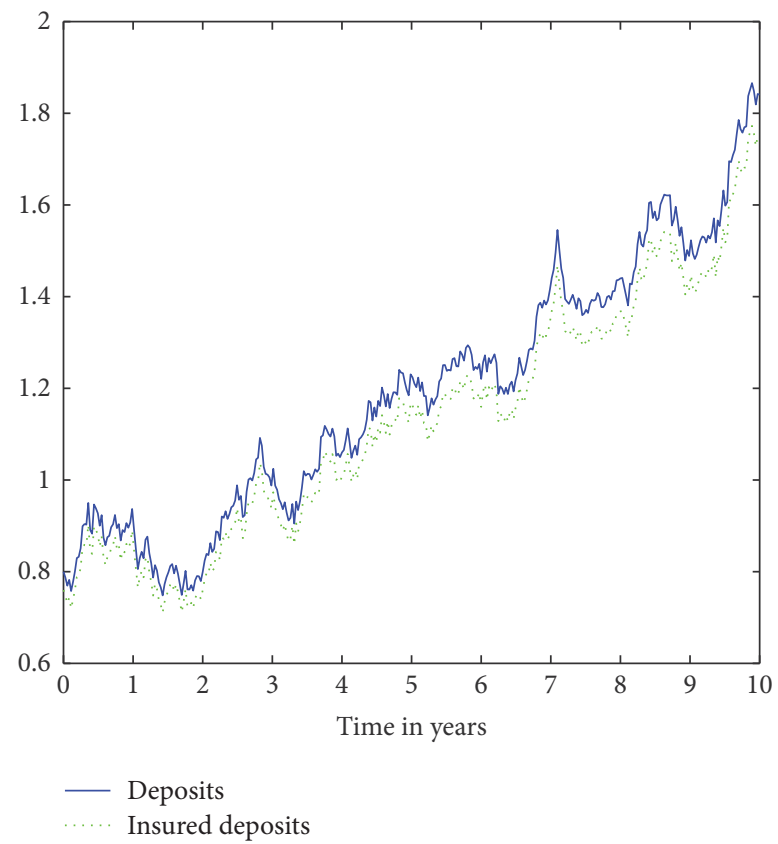

Figure 5: A simulation of the deposits $D(t)$ and insured deposits $\widehat{D}(t)$ for $\mu_{D}=0.12, \sigma_{D}=0.15$, and $\rho=0.95$.

option-like liabilities faced by the insuring agent. Instead, we will employ a Monte Carlo simulation method to calculate an estimate for the price of these liabilities. The deposit insurance premium for the bank can be calculated with the formula (see [16])

$$
\begin{aligned}
\widehat{\omega} & =\frac{1}{n \widehat{D}(0)} \sum_{k=1}^{n} e^{-r t(k)} \mathbb{E} Q(t(k)) \\
& =\frac{1}{n \widehat{D}(0)} \sum_{k=1}^{n} e^{-r t(k)} \mathbb{E}\left[e^{r t(k)} \widehat{D}(t(k))-A(t(k))\right]^{+} .
\end{aligned}
$$

In Algorithm 1, we present the algorithm for the Monte Carlo simulation method that we employed to compute an estimate for $\widehat{\omega}$ for our bank model using Formula (39). The algorithm is given in Algorithm 1.

We simulate the bank's total deposits versus its total insured deposits when $\rho=0.95$ in Figure 5, and the bank's

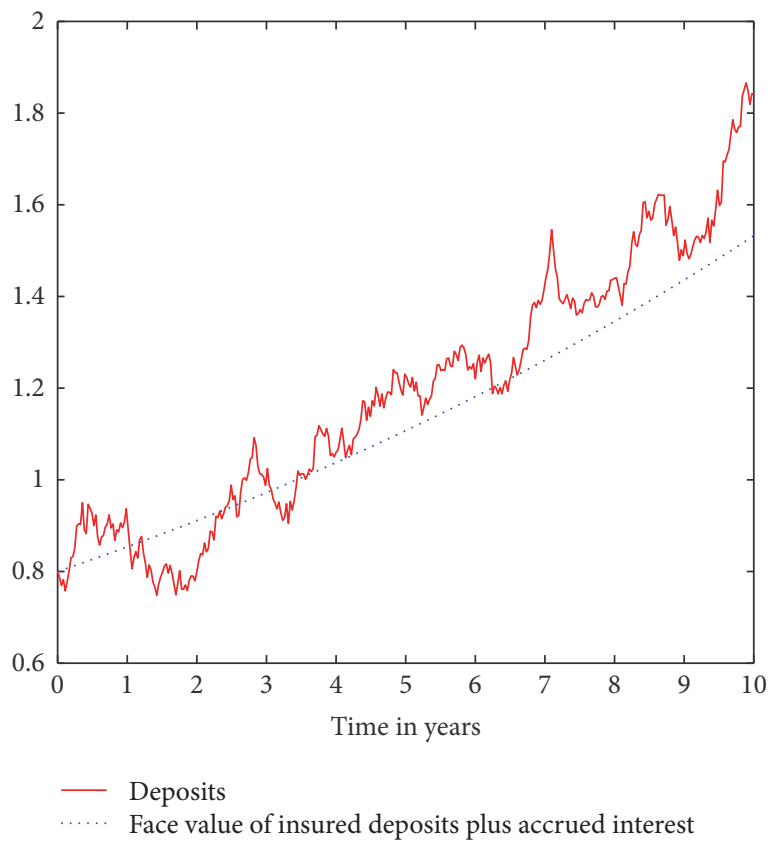

Figure 6: A simulation of the deposits $D(t)$ and the face value of the insured deposits plus accrued interest $e^{r t} \widehat{D}(0)$ for $T=10$ years.

total deposits versus the initial face value of its insured deposits plus accrued interest in Figure 6. We consider the parameter values $\mu_{D}=0.12$ and $\sigma_{D}=0.15$ and initial value $D(0)=0.80$ in the simulations. We note upward trends in the values of all the quantities simulated in the figures. Moreover, the difference between the initial face value of the insured deposits plus accrued interest and the actual total deposits of the bank is relatively small for the better part of the DI coverage horizon.

In Table 1 we present the main results of this section; that is, the simulations we performed with our Monte Carlo simulation method for estimating the premium the bank should be charged for DI. In calculating the estimation for the DI premiums, we have used the same values for the model parameters $r, m_{1}, m_{2}, \sigma_{2}, \sigma_{3}, \mu_{D}, \sigma_{D}$, and $g$ as for the simulations of Section 4 (see Figures 3 and 4 ). For $\sigma_{1}$ and $T$ we consider values ranging, respectively, from 0.08 to 0.16 and 2 
TABLE 1: Estimations for the deposit insurance premium.

\begin{tabular}{|c|c|c|c|c|c|}
\hline$D(0) / A(0)=0.80$ & $\sigma_{1}=0.08$ & $\sigma_{1}=0.10$ & $\sigma_{1}=0.12$ & $\sigma_{1}=0.14$ & $\sigma_{1}=0.16$ \\
\hline$T=2$ & 0.1270 & 0.1336 & 0.1372 & 0.1395 & 0.1410 \\
\hline$T=4$ & 0.2180 & 0.2928 & 0.2991 & 0.3028 & 0.3053 \\
\hline$T=6$ & 0.4426 & 0.4570 & 0.4644 & 0.4687 & 0.4715 \\
\hline$T=8$ & 0.6059 & 0.6213 & 0.6291 & 0.6336 & 0.6363 \\
\hline$T=10$ & 0.7699 & 0.7853 & 0.7927 & 0.7970 & 0.7996 \\
\hline$D(0) / A(0)=0.85$ & $\sigma_{1}=0.08$ & $\sigma_{1}=0.10$ & $\sigma_{1}=0.12$ & $\sigma_{1}=0.14$ & $\sigma_{1}=0.16$ \\
\hline$T=2$ & 0.1477 & 0.1542 & 0.1579 & 0.1600 & 0.1614 \\
\hline$T=4$ & 0.2942 & 0.3044 & 0.3096 & 0.3127 & 0.3147 \\
\hline$T=6$ & 0.4449 & 0.4565 & 0.4624 & 0.4659 & 0.4680 \\
\hline$T=8$ & 0.5966 & 0.6087 & 0.6147 & 0.6181 & 0.6202 \\
\hline$T=10$ & 0.7485 & 0.7602 & 0.7659 & 0.7691 & 0.7711 \\
\hline$D(0) / A(0)=0.90$ & $\sigma_{1}=0.08$ & $\sigma_{1}=0.10$ & $\sigma_{1}=0.12$ & $\sigma_{1}=0.14$ & $\sigma_{1}=0.16$ \\
\hline$T=2$ & 0.1649 & 0.1709 & 0.1742 & 0.1762 & 0.1775 \\
\hline$T=4$ & 0.3033 & 0.3114 & 0.3157 & 0.3182 & 0.3198 \\
\hline$T=6$ & 0.4428 & 0.4518 & 0.4563 & 0.4589 & 0.4605 \\
\hline$T=8$ & 0.5839 & 0.5930 & 0.5974 & 0.5999 & 0.6014 \\
\hline$T=10$ & 0.7247 & 0.7335 & 0.7376 & 0.7400 & 0.7414 \\
\hline$D(0) / A(0)=0.95$ & $\sigma_{1}=0.08$ & $\sigma_{1}=0.10$ & $\sigma_{1}=0.12$ & $\sigma_{1}=0.14$ & $\sigma_{1}=0.16$ \\
\hline$T=2$ & 0.1744 & 0.1823 & 0.1850 & 0.1866 & 0.1877 \\
\hline$T=4$ & 0.3059 & 0.3122 & 0.3154 & 0.3172 & 0.3184 \\
\hline$T=6$ & 0.4368 & 0.4434 & 0.4466 & 0.4485 & 0.4496 \\
\hline$T=8$ & 0.5680 & 0.5745 & 0.5776 & 0.5793 & 0.5804 \\
\hline$T=10$ & 0.7002 & 0.7064 & 0.7093 & 0.7109 & 0.7119 \\
\hline$D(0) / A(0)=1.00$ & $\sigma_{1}=0.08$ & $\sigma_{1}=0.10$ & $\sigma_{1}=0.12$ & $\sigma_{1}=0.14$ & $\sigma_{1}=0.16$ \\
\hline$T=2$ & 0.1832 & 0.1870 & 0.1890 & 0.1901 & 0.1913 \\
\hline$T=4$ & 0.3041 & 0.3085 & 0.3107 & 0.3119 & 0.3127 \\
\hline$T=6$ & 0.4270 & 0.4315 & 0.4337 & 0.4349 & 0.4357 \\
\hline$T=8$ & 0.5503 & 0.5548 & 0.5568 & 0.5579 & 0.5586 \\
\hline$T=10$ & 0.6741 & 0.6784 & 0.6803 & 0.6813 & 0.6819 \\
\hline
\end{tabular}

to 10 years. Also, we consider different initial leverage levels (deposit-to-asset ratios) by varying $D(0)$, but by keeping $A(0)$ fixed at 1.00. The values used for $D(0)$ are $0.80,0.85,0.90,0.95$, and 1.00 .

Our results suggest that the DI premium increases for fixed initial leverage levels and rising $\sigma_{1}$ and $T$ values. This implies that when either the risk in the asset portfolio of the bank or the DI coverage horizon is increased the DI premium also increases. When the initial leverage level is raised by increasing $D(0)$ and keeping $A(0)$ fixed at 1.00 , we notice a downward trend in the estimation for the DI premium as $T$ is increased, but an upward trend in the estimation as we increase $\sigma_{1}$. The first observation is consistent with what was found by Duan and Yu [16] for the case where there is no capital forbearance and moral hazard. The second observation is not consistent with the findings of Duan and $\mathrm{Yu}$ [16].

\section{Conclusion}

This paper considers a banking model that assumes a constant interest rate-financial market consisting of three assets, namely, a treasury, a marketable security, and a loan. Using the method of stochastic optimal control, we show how to optimize the capital of a commercial bank in terms of utility maximization. More specifically, we derive an optimal investment strategy in the bank assets that maximizes an expected exponential utility of the bank's capital at some future date $T>0$. Furthermore, we derive a multiperiod DI pricing model for the bank in question that incorporates the optimal investment strategy and an asset value reset rule similar to the models $[16,19]$ of Duan and Yu.

Our main results are numerical examples illustrating

(i) the optimal investment strategy and corresponding optimized bank capital;

(ii) the effect of changes in various model variables on the DI premium.

The results can be summarized as follows. The optimal investment strategy is to diversify the bank's asset portfolio away from the risky assets and towards the riskless treasury. Under the optimal investment strategy we find that for a fixed initial leverage level (deposit-to-asset ratio) the DI premium will increase when either the risk in the asset portfolio of the 
bank or the DI coverage horizon is increased. For rising initial leverage levels we find that the DI premium will rise as the risk in the asset portfolio is raised but drop as the coverage horizon is increased.

Possible future work on this topic could be to study the behaviours of Basel III's capital adequacy and liquidity ratios for the bank we modelled in this paper. It would be interesting to see whether the bank adheres to the minimum prescribed levels for the aforementioned ratios under the optimal investment strategy derived in this paper. In addition, we could also extend the DI pricing model by incorporating moral hazard, capital forbearance, and systemic risk into the pricing model derived here.

\section{Disclosure}

An earlier version of this work was presented as an abstract at the 60th Annual Congress of the South African Mathematics Society.

\section{Conflicts of Interest}

The author declares that there are no conflicts of interest regarding the publication of this article.

\section{References}

[1] C. H. Fouche, J. Mukuddem-Petersen, and M. Petersen, "Continuous-time stochastic modelling of capital adequacy ratios for banks," Applied Stochastic Models in Business and Industry, vol. 22, no. 1, pp. 41-71, 2006.

[2] J. Mukuddem-Petersen and M. A. Petersen, "Bank management via stochastic optimal control," Automatica, vol. 42, no. 8, pp. 1395-1406, 2006.

[3] J. Mukuddem-Petersen and M. A. Petersen, "Optimizing asset and capital adequacy management in banking," Journal of Optimization Theory and Applications, vol. 137, no. 1, pp. 205230, 2008.

[4] G. E. Muller and P. J. Witbooi, "An optimal portfolio and capital management strategy for basel III compliant commercial banks," Journal of Applied Mathematics, vol. 2014, Article ID 723873, 11 pages, 2014.

[5] F. Chakroun and F. Abid, "An application of stochastic control theory to a bank portfolio choice problem," Statistics and Its Interface, vol. 9, no. 1, pp. 69-77, 2016.

[6] G. J. van Schalkwyk and P. J. Witbooi, "An optimal strategy for liquidity management in banking," Applied Mathematical Sciences, vol. 11, pp. 275-297, 2017.

[7] Basel Committee on Banking Supervision, Basel III: The Liquidity Coverage Ratio and Liquidity Risk Monitoring Tools, 2013.

[8] R. C. Merton, "An analytic derivation of the cost of deposit insurance and loan guarantees An application of modern option pricing theory," Journal of Banking \& Finance, vol. 1, no. 1, pp. 3-11, 1977.

[9] R. C. Merton, "On the cost of deposit insurance when there are surveillance costs," The Journal of Business, vol. 51, no. 3, pp. 439-451, 1978.

[10] A. J. Marcus and I. Shaked, "The valuation of FDIC deposit insurance using option-pricing estimates," Journal of Money, Credit and Banking, vol. 16, no. 4, pp. 446-460, 1984.
[11] J. H. McCulloch, "Interest-risk sensitive deposit insurance premia," Journal of Banking and Finance, vol. 9, no. 1, pp. 137-156, 1985.

[12] E. I. Ronn and A. K. Verma, "Pricing risk-adjusted deposit insurance: an option-based model," The Journal of Finance, vol. 41, no. 4, pp. 871-895, 1986.

[13] G. G. Pennacchi, "A re-examination of the over- (or under-) pricing of deposit insurance," Journal of Money, Credit and Banking, vol. 19, no. 3, pp. 340-360, 1987.

[14] J.-C. Duan, A. F. Moreau, and C. W. Sealey, "Fixed-rate deposit insurance and risk-shifting behavior at commercial banks," Journal of Banking \& Finance, vol. 16, no. 4, pp. 715-742, 1992.

[15] L. Allen and A. Saunders, "Forbearance and valuation of deposit insurance as a callable put," Journal of Banking \& Finance, vol. 17, no. 4, pp. 629-643, 1993.

[16] J.-C. Duan and M.-T. Yu, "Forbearance and pricing deposit insurance in a multiperiod framework," Journal of Risk and Insurance, vol. 61, no. 4, pp. 575-591, 1994.

[17] P. Bartholomew, The Cost of Forbearance during the Thrift Crisis, U.S. Congressional Budget Office Staff Memorandum, Washington, DC, USA, 1991.

[18] G. E. Muller, Optimal asset allocation and capital adequacy management strategies for Basel III compliant banks [Ph.D. thesis], University of the Western Cape, Bellville, South Africa, 2015.

[19] J.-C. Duan and M.-T. Yu, "Capital standard, forbearance and deposit insurance pricing under GARCH," Journal of Banking \& Finance, vol. 23, no. 11, pp. 1691-1706, 1999.

[20] P. Devolder, M. B. Princep, and I. D. Fabian, "Stochastic optimal control of annuity contracts," Insurance: Mathematics \& Economics, vol. 33, no. 2, pp. 227-238, 2003.

[21] P. J. Witbooi, G. J. van Schalkwyk, and G. E. Muller, "An optimal investment strategy in bank management," Mathematical Methods in the Applied Sciences, vol. 34, no. 13, pp. 1606-1617, 2011.

[22] Basel Committee on Banking Supervision, Basel III: A Global Regulating Framework for More Resilient Banks and Banking Systems, 2010.

[23] M. A. Petersen and J. Mukuddem-Petersen, Basel III Liquidity Regulation and Its Implications, Business Expert Press, McGrawHill, New York, NY, USA, 2013.

[24] J. Gao, "Stochastic optimal control of DC pension funds," Insurance: Mathematics \& Economics, vol. 42, no. 3, pp. 11591164,2008

[25] Q.-P. Ma, “On 'Optimal pension management in a stochastic framework' with exponential utility,' Insurance: Mathematics \& Economics, vol. 49, no. 1, pp. 61-69, 2011.

[26] C. Zhang and X. Rong, "Optimal investment strategies for dc pension with stochastic salary under the affine interest rate model," Discrete Dynamics in Nature and Society, vol. 2013, Article ID 297875, 11 pages, 2013.

[27] D. Kramkov and W. Schachermayer, "The asymptotic elasticity of utility functions and optimal investment in incomplete markets," The Annals of Applied Probability, vol. 9, no. 3, pp. 904-950, 1999.

[28] M. Jonsson and R. Sircar, "Optimal investment problems and volatility homogenization approximations," in Modern Methods in Scientic Computing and Appllications, A. Bourliux, M. Gander, and G. Sabidussi, Eds., vol. 75 of NATO Science Series II, pp. 255-281, Kluwer, 2002.

[29] F. Black and M. Scholes, "The pricing of options and corporate liabilities," Journal of Political Economy, vol. 81, no. 3, pp. 637654, 1973. 


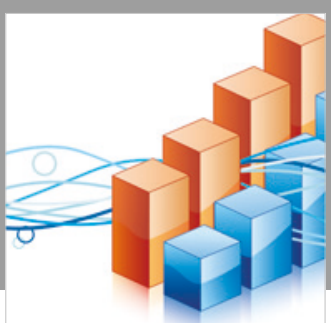

Advances in

Operations Research

\section{-n-m}
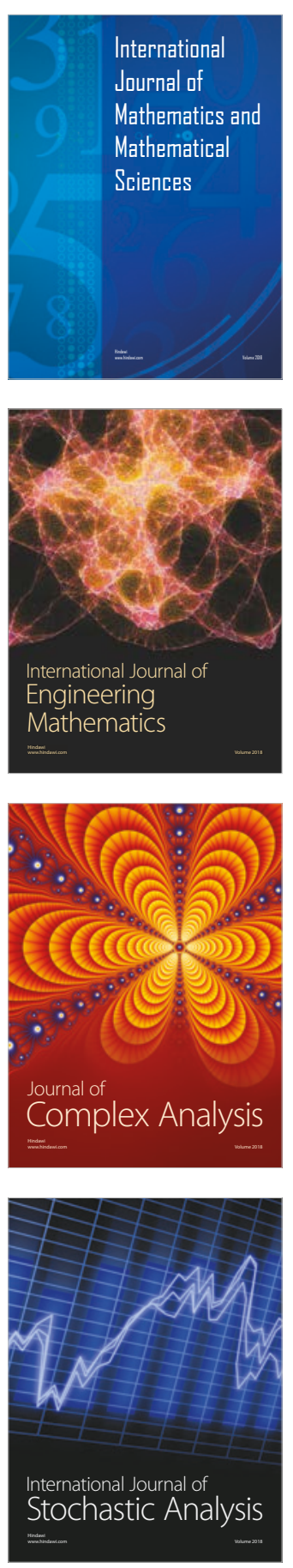
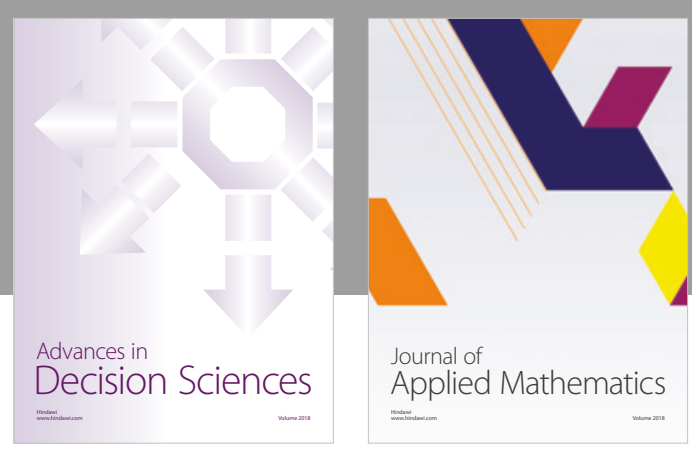

Journal of

Applied Mathematics
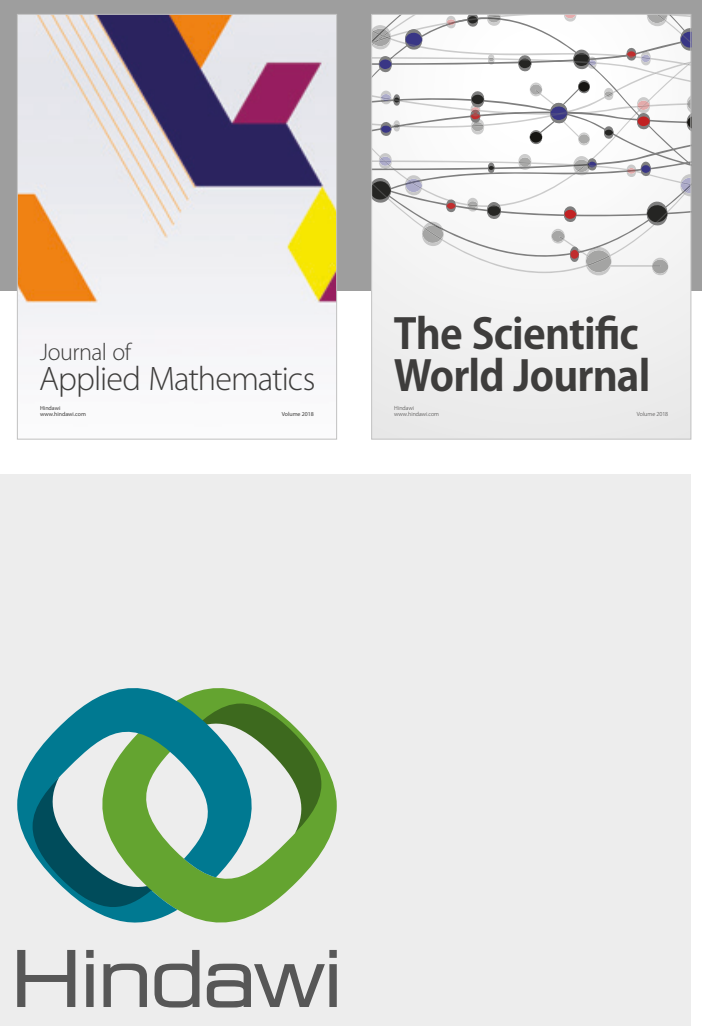

Submit your manuscripts at

www.hindawi.com

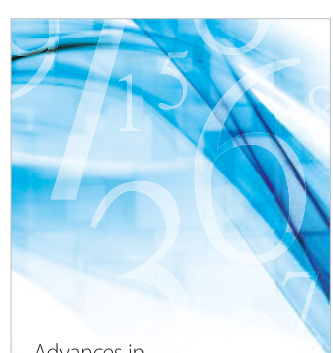

Advances in
Numerical Analysis
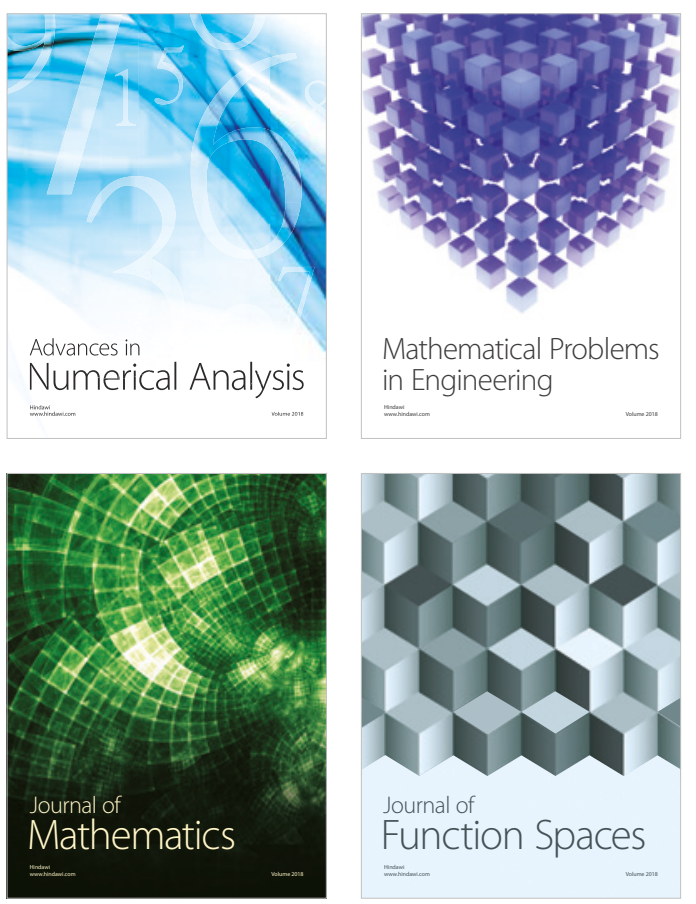

Mathematical Problems in Engineering

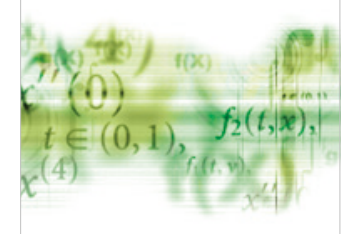

International Journal of

Differential Equations

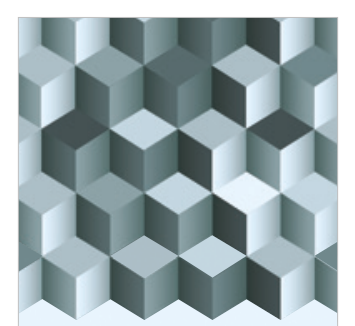

Journal of

Function Spaces

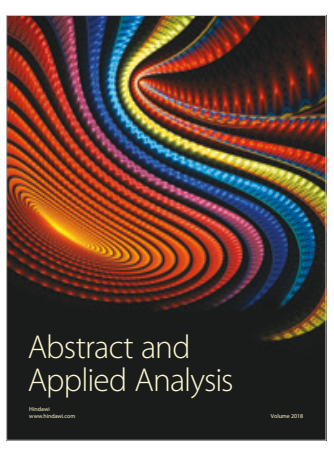

The Scientific

World Journal

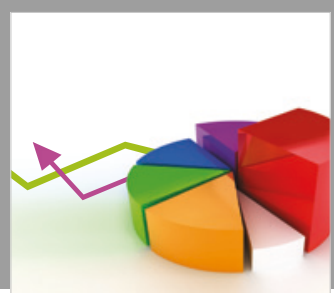

Journal of

Probability and Statistics
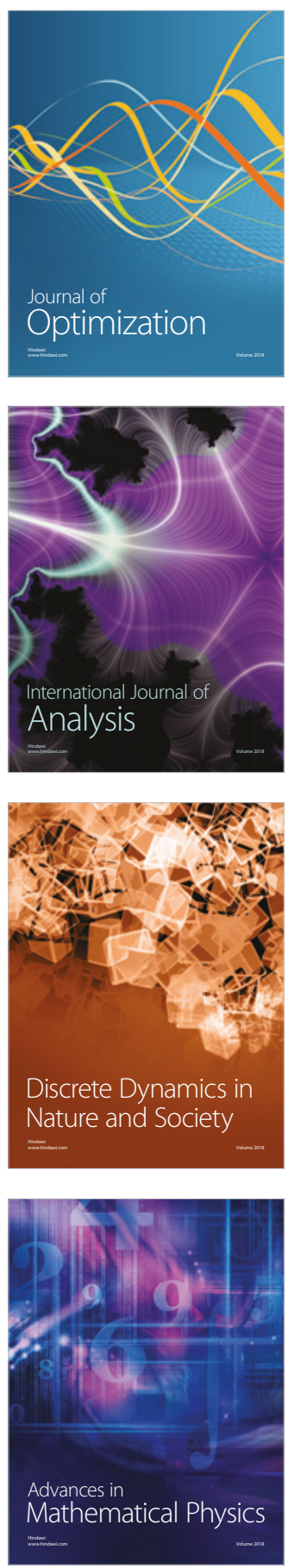